\title{
Contradições das políticas públicas voltadas para doenças raras: o exemplo do Programa de Tratamento da Osteogênese Imperfeita no SUS
}

\author{
Contradictions of public health policies geared to rare disorders: \\ the example of the Osteogenesis Imperfecta Treatment Program \\ in the Brazilian Unified Health System (SUS)
}

Maria Angelica de Faria Domingues de Lima ${ }^{1}$

Dafne Dain Gandelman Horovitz ${ }^{2}$

\footnotetext{
${ }^{1}$ Pós-Graduação em Saúde da Criança e da Mulher, Instituto Nacional de Saúde da Mulher, da Criança e do Adolescente Fernandes Figueira, Fiocruz. Av. Rui Barbosa 716, Flamengo. 22.250-020 Rio de Janeiro RJ Brasil. mangelicafdl@gmail.com ${ }^{2}$ Departamento de Genética Médica, Instituto Nacional de Saúde da Mulher, da Criança e do Adolescente Fernandes Figueira, Fiocruz.
}

\begin{abstract}
The scope of this paper is to examine the process of consolidation of a public health policy in Brazil geared to a rare disorder, namely osteogenesis imperfecta, the treatment for which has fallen under the responsibility of the Brazilian Unified Health System (SUS) after the publication of Ministerial Ruling GM/MS2305/2001. The implementation of this law has been accompanied by many contradictions, especially with respect to therapeutic decisions and the strengthening of the specialized network for addressing this condition. These attitudes are clearly shown both by the drafting process and the final text of the new law (Ministerial Ruling 714/2010).

Key words Osteogenesis imperfecta, Public health policy, Rare disorders
\end{abstract}

Resumo O artigo visa discutir o processo de consolidação de uma política pública, no Brasil, voltada a uma doença rara - a osteogênese imperfeita, cujo tratamento passou a responsabilidade do SUS em 2001 através da Portaria GM/MS2305/ 2001. O processo de implementação desta terapia vem sendo acompanhado de contradições, sobretudo no que diz respeito às decisões terapêuticas e ao fortalecimento da rede especializada na abordagem desta condição, atitudes claramente percebidas tanto no processo de elaboração quanto no texto da nova Portaria 714/2010.

Palavras-chave Osteogênese imperfeita, Politicas públicas de saúde, Doenças raras 
Introdução - a Osteogenese Imperfeita

A osteogênese imperfeita (OI) é uma doença rara, caracterizada por fragilidade óssea, fraturas recorrentes com deformidades secundárias, surdez precoce, escleras azuladas e dentinogênese imperfeita. A OI está associada a mutações nos genes do colágeno tipo 1 ou em genes responsáveis pelo processamento da proteína do colágeno tipo 1. A alteração da fibra do colágeno é o ponto central de sua fisiopatologia ${ }^{1}$. Sua frequência varia entre 6-7:100.000 indivíduos ${ }^{1}$ e no Brasil estima-se que existam 12.000 indivíduos com tal diagnóstico ${ }^{2}$. Doenças raras são definidas como aquelas que afetam um número limitado de indivíduos na população, ou cuja prevalência é menor que 1:2000 ${ }^{3}$.

Um dos marcos no estudo da condição foi a classificação descrita por Sillence et al. ${ }^{4}$ que permitiu distribuir os indivíduos afetados em quatro diferentes tipos, de acordo com as manifestações clínicas apresentadas. Tal classificação sempre esteve intimamente relacionada a fatores prognósticos ${ }^{5}$ e vem sendo ampliada e revista conforme o surgimento de novos conhecimentos acerca da doença ${ }^{6}$.

O tratamento da OI fundamenta-se na abordagem multidisciplinar - clínico-cirúrgica e reabilitação fisioterápica. Uma grande transformação em sua terapia começou a ser delineada em 1987 com o primeiro relato sobre os benefícios dos bifosfonatos ${ }^{7}$, e, em 1998, após a publicação de estudos envolvendo grande número de pacientes $^{8,9}$, esse tipo de fármaco consolidou-se como primeira escolha na terapêutica medicamentosa aplicada à condição. Os bifosfonatos são compostos com grande capacidade de inibição do turnover ósseo. $\mathrm{Na} \mathrm{OI}$, o beneficio do uso destas medicações pode ser percebido clinicamente pela redução do número de fraturas e da dor óssea, tão frequentes entre estes pacientes.

\section{O tratamento da Osteogenese Imperfeita no SUS: portarias, evidências e incongruências}

No Brasil, o tratamento da OI é disponibilizado pelo SUS desde 2001, com a instituição da Portaria GM 2305/2001 ${ }^{10}$. O estabelecimento desta portaria no país é reflexo da organização e participação da sociedade civil na discussão acerca das políticas públicas de saúde. No caso da OI, os interesses do grupo de indivíduos afetados são representados pela Associação Brasileira de Osteogênese Imperfeita.
A Portaria 2305/2001 definiu: (1) a criação e normas para o cadastramento de centros de referencia em OI no território nacional; (2) elegibilidade para tratamento; (3) a medicação a ser utilizada nestes centros - o pamidronato dissódico (PD), assim como sua dose e as medicações complementares; (4) exames complementares necessários para o acompanhamento de um indivíduo em tratamento e, por fim, (5) a criação e a manutenção de um banco de dados de OI, sob responsabilidade do Instituto Nacional de Saúde da Mulher, da Criança e do Adolescente Fernandes Figueira da Fundação Oswaldo Cruz (INSMCA/Fiocruz $)^{10}$.

Embora tenha sido um grande passo na direção da implementação de uma política pública voltada a uma doença rara no país, a Portaria 2305/2001 possuía muitas inconsistências. À época, a literatura especializada indicava como critérios para início de tratamento o número de fraturas anual, a presença de dor óssea e deformidades em ossos longos, não apresentando restrições quanto ao tipo de OI, nem idade para início da medicação. No entanto, a Portaria 2305/2001 restringia o emprego do $\mathrm{PD}$ em indivíduos com OI dos tipos I, III e IV, e, ainda apresentava um texto ambíguo no que se referia a idade para inclusão no tratamento, tomando como critério idade até 21 anos, entretanto estabelecendo códigos para pagamento do tratamento em adultos ${ }^{10}$.

Desde 2001, 14 centros de referência foram cadastrados e estão em atividade no país. A maior parte deles se concentra nos estados das regiões sul e sudeste, o que dificulta o acesso ao tratamento de muitos pacientes. Centros de referência podem ser definidos como "local adequado para referir pacientes, por sua experiência e disponibilidade de serviços"3. O perfil de um centro de referencia é variável, indo desde um espaço focado no diagnóstico e tratamento de doenças raras e ou complexas até a pesquisa clínica com vistas à produção de diretrizes assistenciais e fornecimento de pareceres por especialistas.

A partir de uma revisão abrangente da literatura científica percebe-se que as publicações sobre OI oriundas do Brasil são escassas. Pouco mais de 10 estudos podem ser identificados e apenas três lidam com questões relacionadas ao tratamento $^{11}$. No mundo, desde os trabalhos mais importantes divulgados em 1998, mais de 400 pesquisas sobre o tratamento da OI foram publicadas. Uma vez que o referido tratamento é uma política pública de saúde e que existem centros voltados para o acompanhamento e a prestação de cuidados a esta condição no país, com número 
significativo de pacientes a eles vinculados - somente no centro de referência do INSMCA/ FIOCRUZ este número ultrapassa 160 pacientes, se torna ainda mais expressivo o pequeno número de estudos brasileiros sobre a doença. Cabe ressaltar que a pesquisa clínica não pode e não deve, em nenhuma hipótese, ser separada da prática médica. Zago ${ }^{12}$ afirma que "a pesquisa tem por objetivo criar novos conhecimentos ou reorganizar o conhecimento já existente pela análise crítica". E ainda, sugere que temas de pesquisa devem balizar-se na importância de "adquirir nossa própria experiência: o Brasil precisa obter seus próprios dados, formular políticas próprias e resolver problemas específicos do país"12, enfatizando o observado por Salzano no tocante às doenças genéticas no Brasil apresentarem, por vezes, padrões de mutações e correlações genótipo/fenótipo que diferem do restante do mun$\mathrm{do}^{13}$. Dentro dessa lógica, considerando a raridade da OI, a importância de conhecer seus dados epidemiológicos e clínicos ganha ainda mais peso, uma vez que tais informações irão refletir na melhor abordagem frente ao diagnóstico, tratamento e até mesmo nas consequências sociais de uma determinada enfermidade ${ }^{3}$.

A construção desta política de saúde no país baseou-se em poucos estudos publicados sobre tratamento da OI com bifosfonatos no período 1998 - data das primeiras séries de $\operatorname{casos}^{8,9}$ - e 2002. Pela escassez de dados à época de sua publicação e, principalmente pela inexistência de dados brasileiros, um trabalho canadense norteou o Programa Brasileiro de OI. Apesar de admirável em seu pioneirismo, as inconsistências foram sendo percebidas e discutidas pelos especialistas em OI no país, que adaptaram a política às novas evidências e às necessidades de cada região.

Em novembro de 2010 foi lançada uma consulta pública para atualização do Protocolo Clínico e Diretrizes Terapêuticas - Osteogenesis Imperfecta $^{14}$. Sem dúvida que essa iniciativa representou o surgimento de um espaço para discussão da terapêutica da OI no país, contudo aconteceu sem engajar a participação dos especialistas que atuavam nos centros de referência, o que pode ser facilmente percebido pelos equívocos relacionados à caracterização da doença, seu diagnóstico e acompanhamento. O texto que embasava tal consulta pública falhou em alguns pontos: (1) ao estabelecer que a ausência de história familiar excluía o diagnóstico de OI; (2) ao não reconhecer os tipos clínicos que haviam sido descritos até a época; e (3) as propostas para tratamento não consideraram estudos que sugeriam absorção errática de alendronato ${ }^{15}$. Ademais, ignorar a própria rede especializada, proposta via a Portaria 2305/2001 alvo de tal atualização, minimamente constituiu um contrassenso.

A nova portaria 714/2010 definiu critérios para: (1) diagnóstico de OI; (2) início do tratamento com o PD e também com o alendronato dissódico, outra medicação do grupo dos bifosfonatos; (3) interrupção do tratamento, além de parâmetros clínicos para avaliação da resposta terapêutica ${ }^{16}$. Consideráveis avanços foram passíveis de serem constatados, sobretudo os referentes à possibilidade de tratamento em esquema de hospital-dia, diminuindo admiravelmente os custos de uma internação mais prolongada, o risco de possíveis infecções hospitalares e a ruptura mais prolongada da vivência cotidiana dos pacientes e suas famílias. No entanto, em que pese esses pontos positivos a nova portaria ainda apresenta falhas, como veremos a seguir.

A elaboração desse novo documento seguiu o proposto pela Secretaria de Atenção à Saúde através da portaria 375/2009 que estabeleceu um roteiro para a preparação de Protocolos Clínicos e Diretrizes Terapêuticas ${ }^{17}$. O texto, que inicia explicitando a metodologia de busca das evidências científicas na literatura especializada, identificou 10 estudos clínicos randomizados ou metaanálises sobre tratamento medicamentoso da OI que embasaram a construção das novas diretrizes. Os ensaios clínicos controlados e randomizados são o "padrão-ouro" de evidência sobre efeitos de uma intervenção. A qualidade desses estudos é associada à tentativa de eliminação de vieses que possam surgir no âmbito da pesquisa clínica. No entanto, eles possuem limitações, sendo a principal a elaboração de amostras de pacientes estritamente, o que por um lado aumenta sua validade interna, por outro impede a generalização de seus resultados para populações heterogêneas ${ }^{18}$. Assim, os estudos controlados tentam sobrepor este entrave através da construção de amostras numerosas, o que no caso das doenças raras torna-se difícil. Souza et al. ${ }^{19}$ recomendam a criação de uma "política farmacêutica específica para doenças raras”, amparados, entre outros fatores, pela pouca disponibilidade de fortes evidencias para a maior parte dos tratamentos disponíveis para doenças genéticas como é o caso em questão.

Como exemplo do acima afirmado, a nova Portaria suprimiu dos parâmetros clínicos exames complementares relacionados à avaliação do turnover ósseo. Tendo em vista que os bifosfonatos têm como mecanismo de ação a inibição 
da reabsorção óssea ao interferirem na ação dos osteoclasto $^{20}$, o acompanhamento do turnover ósseo é uma importante ferramenta para análise de sua resposta terapêutica ${ }^{9}$. Da mesma forma, os exames de densitometria óssea não são mais contemplados.

A interrupção do tratamento também foi definida, recomendando a suspensão da droga depois de dois anos sem apresentar fraturas. Alguns estudos apontam a estabilização dos ganhos ósseos após alguns anos do uso do PD. Porém, a descontinuidade do uso da medicação pode ter efeitos deletérios para a mineralização óssea, sobretudo em indivíduos que ainda não completaram o crescimento do seu esqueleto ${ }^{21}$.

Nesse cenário, portanto, a discussão sobre modos de manter os benefícios auferidos pela terapia medicamentosa é mais do que oportuna. Em centros de referencia mundiais após a estabilização dos ganhos de massa óssea e do turnover ósseo, o tratamento é continuado com doses anuais menores de PD até a maturação do esqueleto, sendo reavaliado em momento oportu$\mathrm{no}^{22}$. Na nova portaria, contudo, as recomendações para acompanhamento pós-tratamento são incompletas. O texto indica exclusivamente o acompanhamento clínico e recomenda que somente com o surgimento de fraturas outros exames deverão ser realizados, claramente não mirando estratégias de prevenção de agravos. $\mathrm{Na}$ OI as fraturas são a extremidade aparente de uma cadeia de eventos que ocorre na microarquitetura óssea. O desbalanceamento do turnover ósseo em favor da reabsorção, a diminuição de trabéculas ósseas e da espessura cortical são algumas das características que precedem a fratura e que podem ser avaliadas através de exames complementares como a dosagem dos marcadores de turnover ósseo, radiografias, densitometria óssea, entre outros ${ }^{21}$.

Prosseguindo, cabe ainda ressaltar que o papel dos centros de referencia não foi claramente estabelecido pelo novo documento. Lê-se no seu texto:

pacientes com diagnóstico de OI, dependendo da idade, devem ser atendidos em serviços especializados com capacidade de atendimento médico, inclusive ortopédico e fisioterápico. Tais serviços serão responsáveis pela indicação do tratamento, inclusive com bifosfonato oral (alendronato) [...]. A regulação do SUS deve organizar os fluxos de internações e acompanhamento ambulatoriais. Portaria 714/2010 ${ }^{16}$.

Dentre as normas da Portaria 2305/2001 estava a exigência de cadastramento dos hospitais para tratamento da OI, de acordo com o indicado pelo Ministério da Saúde no que tange aos procedimentos de alta complexidade no sistema, ressaltando-se o reconhecimento da OI, assim como da genética clínica como partes desta esfera hierárquica $^{23}$. Os mesmos deviam se adequar aos requisitos básicos que exigiam, entre outros, a existência de um responsável técnico - um médico com experiência em OI, equipe multidisciplinar, recursos para internação, atendimento ambulatorial, diagnóstico laboratorial e de imagem. Embora a flexibilização das exigências seja um facilitador para a expansão da rede de tratamento da OI, a moderação dos requisitos pode levar ao surgimento de equipes pouco capacitadas para lidar com os desafios impostos por ela face sua raridade, sua complexidade clínica e etiológica.

Ademais, a regulação de vagas para internação deve levar em conta a internação de mais de um paciente ao mesmo tempo, no mesmo local, com vistas ao compartilhamento de doses de medicamento, diminuindo seu desperdício, e, por outro lado, considerar o melhor aproveitamento da equipe de saúde e não somente a disponibilidade de vagas. A ambiguidade na definição dos locais de tratamento é um retrocesso no fortalecimento da rede de centros de referência para doenças raras no país.

À guisa de sintetizar e elaborar algumas considerações finais devemos recordar que a nova Portaria incluiu outros tipos de OI nos critérios para tratamento, além de contemplar o uso de medicações orais, embora sejam escassos os estudos que favoreçam o uso de alendronato na OI. Todavia, a exclusão de parâmetros laboratoriais do acompanhamento de pacientes com OI deve ser tomada com cautela, sobretudo após a interrupção do tratamento medicamentoso. Os efeitos deletérios clinicamente identificáveis da doença, as fraturas e as deformidades, são a consequência de alterações fisiopatológicas na microarquitetura óssea que podem, por vezes, ser precocemente inferidos pelos exames complementares.

Os centros de referencia possuem todo o potencial para serem pontos centrais na implantação de tais políticas em território nacional. A existência de tais centros justifica-se pelo previamente exposto e pode ser sintetizado em (1) melhorar o acesso ao tratamento das doenças raras ao reunir experiência clínica e infraestrutura em locais determinados, o que também impacta o seu custo; (2) superar a inexperiência dos profissionais que lidam com doenças raras, uma vez que (re)conhece-las requer grandes investimentos no 
treinamento destes indivíduos ${ }^{3}$; e, (3) a capacidade que tais centros dispõe para produzir conhecimentos sólidos através de pesquisas cientificas favorecendo a apreciação da nossa realidade. É interessante notar que, já em 2001, a política de tratamento da OI reconhecia as vantagens da construção de uma rede de centros de referência integrada, assim como as políticas atuais voltadas para outras doenças raras, tal como a doença de Gaucher, também a reconhecem ${ }^{24}$, o que, talvez, seja o modo mais adequado de atingir os objetivos propostos por uma das poucas políticas públicas brasileiras voltadas ao atendimento de indivíduos com doenças raras.

\section{Colaboradores}

MAFD Lima e DDG Horovits participaram da pesquisa, metodologia, concepção final e preparação do manuscrito. 


\section{Referências}

1. Steiner RD, Pepin MG, Byers PH. Osteogenesis Imperfecta. In: Pagon RA, Bird TD, Dolan CR, Stephens K, Adam MP, editors. Gene Reviews ${ }^{T M}$ [Internet]. Seattle (WA): University of Washington; 2005. p. 1993-2013.

2. Associação Brasileira de Osteogenese Imperfeita. $O$ que é OI? [página na Internet]. [acessado 2012 abr 20]. Disponível em: http://www.aboi.org.br/oqueeh.html

3. Rare Disease Task Force Working Group. Centers of Reference for rare disease in Europe: State-of-theart in 2006 and Recommendations of the Rare Disease Task Force. Report; 2006 Dez [acessado 2012 maio 5]:[cerca 39p.]. Disponível em: http://ec. europa.eu/health/archive/ph_threats/non_com/ docs/contribution_policy.pdf.

4. Sillence DO, Senn A, Danks DM. Genetic heterogeneity in osteogenesis imperfecta. J Med Genet 1979; 16(2):101-116.

5. Moreira CLM, Lima MAFD, Cardoso MHCA, Gomes Júnior SCS, Lopes PB, Llerena Júnior JC. Determinantes da marcha independente na osteogênese imperfeita. Acta Ortop Bras. 2010; 19(5):312-315.

6. Van Dijk FS, Pals G, Van Rijn RR, Nikkels PG, Cobben JM. Classification of Osteogenesis Impefecta revisited. Eur J Med Genet 2010; 53(1):1-5.

7. Devogelaer JP, Malghem J, Maldague B, Nagant de Deuxchaisnes C. Radiological manifestations of bisphosphonate treatment with APD in a child suffering from osteogenesis imperfecta. Skel Radiol 1987; 16(5):360-363.

8. Aström E, Söderhäll S. Beneficial effect of bisphosphonate during five years of treatment of severe osteogenesis imperfecta. Acta Paediatrica 1998; 87(1):6468.

9. Glorieux FH, Bishop NJ, Plotkin H, Chabot G, Lanoue G, Travers R. Cyclic administration of pamidronate in children with severe osteogenesis imperfecta. N Engl J Med 1998; 339(14):947-952.

10. Brasil. Ministério da Saúde (MS). Portaria no 2305/ 2001, de 19 de dezembro de 2001. Aprova o Protocolo de Indicação de Tratamento Clínico da osteogenesis imperfecta com pamidronato dissódico no âmbito do Sistema Único de Saúde - SUS. Diário Oficial da União 2001; 20 dez.

11. Lima MAFD. Aplicação clínica da evidência científica: o caso da osteogênese imperfeita e o tratamento medicamentoso com bifosfonatos [dissertação]. Rio de Janeiro: Fundação Oswaldo Cruz; 2010.

12. Zago MA. A pesquisa clínica no Brasil. Cien Saude Colet 2004; 9(2):363-374.

13. Salzano FM. Saúde pública no primeiro e terceiro mundos: desafios e perspectivas. Cien Saude Colet 2002; 7(1):7-16.
14. Brasil. Ministério da Saúde (MS). Secretaria de Atenção à Saúde. Consulta Pública n ${ }^{\circ} 40$, de 10 de novembro de 2010. Submete a consulta pública o Protocolo Clínico e Diretrizes Terapêuticas - Osteogênese Imperfeita. Diário Oficial da União 2010; 11 nov.

15. Ward LM, Denker AE, Porras A, Shugarts S, Kline W, Travers R, Mao C, Rauch F, Maes A, Larson P, Deutsch P, Glorieux FH. Single-dose pharmacokinetics and tolerability of alendronate 35 - and 70milligram tablets in children and adolescents with Osteogenesis imperfecta type I. J Clin Endocrinol Metab 2005; 90:4051-4056.

16. Brasil. Ministério da Saúde (MS). Portaria $n^{\circ} 714$, de 17 de dezembro de 2010. Aprova o Protocolo Clínico e Diretrizes Terapêuticas - Osteogênese Imperfeita. Diário Oficial da União 2010; $22 \mathrm{dez}$.

17. Brasil. Ministério da Saúde (MS). Portaria $n^{\circ} 375$, de 10 de novembro de 2009. Aprova o roteiro a ser utilizado na elaboração de Protocolos Clínicos e Diretrizes Terapêuticas no âmbito da Secretaria de Atenção à Saúde. Diário Oficial da União 2009; 11 nov.

18. Sackett DL, Haynes RB, Guyatt GH, Tugwell P. Clinical Epidemiology: a basic science for clinical medicine. Boston, Toronto, London: Little, Brown and Company; 1992.

19. Souza MV, Krug BC, Picon PD, Schwartz IVD. Medicamentos de alto custo para doenças raras no Brasil: o exemplo das doenças lisossomicas. Cien Saude Colet 2010; 15(Supl. 13):3443-3454.

20. Russel RGG, Rogers MJ. Bisphosphonates: From the laboratory to the clinic and back again. Bone 1999; 25(1):97-106.

21. Rauch F, Munns C, Land C, Glorieux FH. Pamidronate in children and adolescents with osteogenesis imperfecta: effect of treatment discontinuation. J Clin Endocrinol Metab 2006; 91(4):1268-1274.

22. Rauch F. Declaração pessoal ao autor. Montreal; 2008.

23. Brasil. Ministério da Saúde (MS). O SUS de A a Z. Garantindo a saúde nos municípios. Brasília: Editora do Ministério da Saúde; 2009.

24. Brasil. Ministério da Saúde (MS). Portaria $n^{\circ} 708$, de 25 de outubro de 2011. Aprova o Protocolo Clínico e Diretrizes Terapêuticas - Doença de Gaucher. Diário Oficial da União 2011; out 26.

Artigo apresentado em 28/08/2012

Aprovado em 28/09/2012

Versão final apresentada em 30/09/2012 